\title{
Thoughts and Progress
}

\section{Renal Transplantation by Automatic Anastomotic Device in a Porcine Model}

\author{
Attilio Ignazio Lo Monte, Giuseppe Damiano, \\ Vincenzo Davide Palumbo, Gabriele Spinelli, \\ and Giuseppe Buscemi \\ Department of Surgical, Oncological, and \\ Stomatological Disciplines, University of Palermo, \\ Palermo, Italy
}

\begin{abstract}
Automatic vascular staplers for vascular anastomoses in kidney transplantation may dramatically reduce the operative time and, in particular, warm ischemia time, thus increasing the outcome of transplantation. Ten pigs underwent kidney auto-transplantation by automatic anastomotic device. Kidneys were collected by laparotomy with selective ligations at the renal hilum and perfused with cold storage solution. To overcome the shortage in length of renal hilum, a tract of the internal jugular vein was harvested to increase the length of the vessels. The anastomoses were totally performed by the use of the anastomotic device. On 10 kidney transplants, nine were successful and no complications occurred. Renal resistive indexes showed a slight increase in the immediate postoperative period returning normal at 10 days of follow-up. We demonstrated the possibility to perform renal vascular anastomoses by means of an automatic anastomotic device. This instrument developed for coronary bypass surgery by virtue of the small caliber of the vessels could be adopted on a larger scale for renal transplantation. The reduced warm ischemia time needed for anastomosis may help to achieve a better outcome for the graft and expand the pool of marginal donors in renal transplantation. Key Words: Anastomosis device-Mechanical vascular sutures-Kidney transplantation-Vascular anastomosisWarm ischemia time.
\end{abstract}

Although technologies tend to substitute human hands in different contexts due to the better results achievable with their development, this statement could be partially correct in the field of vascular surgery, and the hand-sewn anastomosis still overtakes for quality anastomoses that can be achieved by devices presently in the market. Like the finest

doi:10.1111/aor.12467

Received June 2014; revised October 2014

Address correspondence and reprint requests to Giuseppe Damiano, Department of Surgical, Oncological, and Stomatological Disciplines, University of Palermo, Via del Vespro 129, 90127 Palermo, Italy. E-mail: giuse.damiano@gmail.com fashion accessories, "hand-sewn" holds a bigger value. Manual suturing remains the gold standard for creating vascular anastomoses $(1,2)$ independently of the size of blood vessels. Vascular anastomoses need good technical skills from a surgeon (3). In the last few years, many different devices have been developed to comply with the increasing demand for an easy, time-saving, less damaging, and reliable procedure to create vascular anastomosis in organ transplant surgery (4). One of the fields of major interest of researches in organ transplant is currently the recovery of marginal organs-a concept that passes from the reduction of warm ischemia time-by using better perfusion solutions more capable of preserving cell function, and technical stratagems developed for this purpose. The reduction of this unavoidable time is thought to be crucial for graft function, especially with the increased use of marginal donors to encompass a long waiting list for people who need a transplant (5).

Recent papers have tested the feasibility of vascular anastomoses made by Cardica C-Port Flex-A (6). This device (Fig. 1), approved by the US Food and Drugs Administration, is currently used in cardiothoracic surgery for cardiac bypass revascularization. The use of this device had been supported by several studies that did not show differences in the patency rate of C-Port technology and hand-sewn sutures $(6,7)$. The same device was also recently tested with success in arteriovenous fistula creation (8) and in experimental settings for neurosurgery $(9,10)$. From these previous experiences, we investigated, on an in vivo large animal model, the possibility to perform vascular anastomoses during kidney transplantation

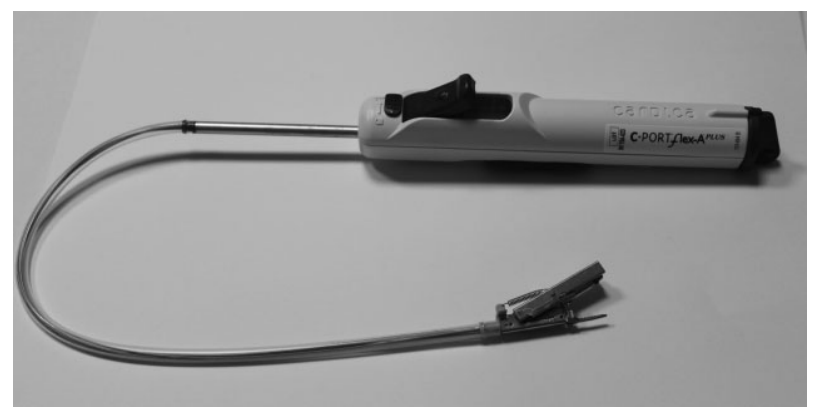

FIG. 1. The Cardica C-Port Flex-A Anastomosis System. 
by using the Cardica C-Port Flex-A system device and, subsequently, reduce dramatically the warm ischemia time.

\section{MATERIALS AND METHODS}

For our study, 12 female Landrace pigs weighing a mean of $27.72 \mathrm{~kg}(\mathrm{SD} \pm 1.72)$, with a median age of 4 months, were used. Surgical procedures previously received authorization from the Ethic Committee of Istituto Zooprofilattico “A. Mirri” of Palermo, Italy and were conducted in this facility in adherence to International Guidelines for Animal Experiment (11).

\section{Study design}

A morpho-anatomical study of the abdomen and pelvis to assay the kidney's dimensions, length and diameters of renal hilum (Fig. 2) and iliac vessels, was conducted on the first two pigs.

Ten pigs were used to perform renal autotransplantation by means of the C-Port Flex-A stapler (Cardica, Inc., Redwood City, CA, USA) with a single-time arterial and venous anastomosis (cut and sewn system).

\section{C-Port Flex-A plus distal anastomosis system}

The C-Port Flex-A plus distal anastomosis system is a single-use tool that integrates the functions necessary to perform an end-to-side anastomosis in about $15 \mathrm{~s}$, delivering 13 stainless steel micro staples that circumferentially connect the graft to the target vessel in a compliant fashion. The device is composed of three parts: (i) the handler that contains the $\mathrm{CO}_{2}$ reservoir for pneumatic/gas-driven anastomosis and the trigger lever; (ii) the flexible neck; and (iii) the

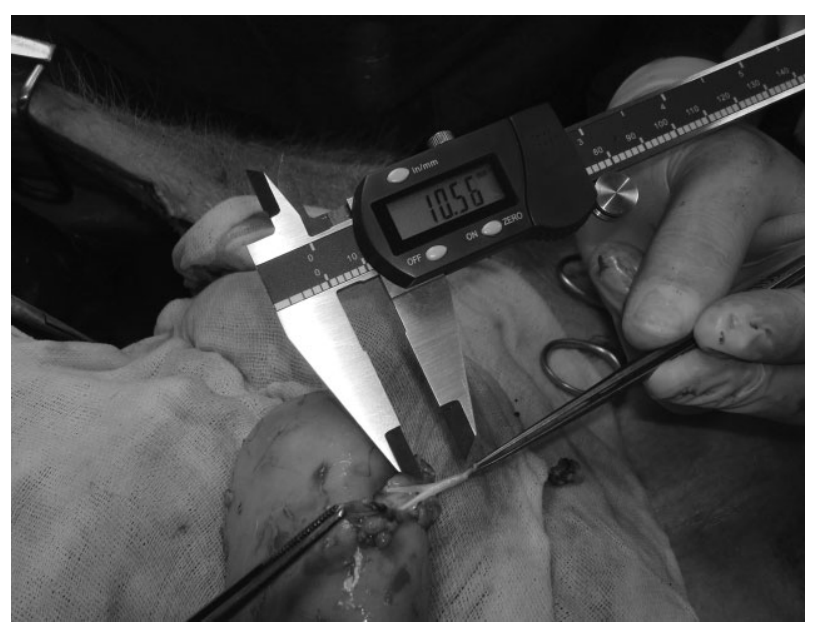

FIG. 2. Measurement of renal artery length and caliber.

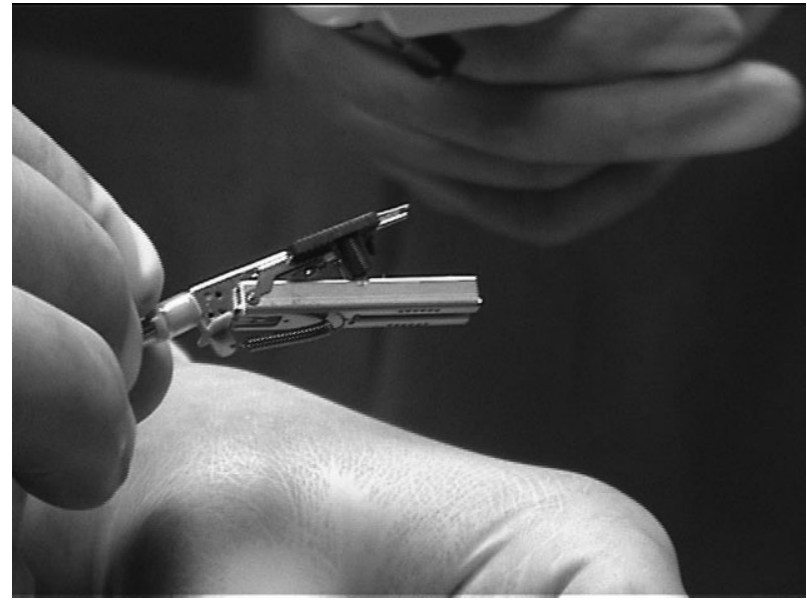

FIG. 3. The cartridge assembly of Cardica prepared to be inserted in the iliac artery.

cartridge assembly (Fig. 3). The last part contains the staples and clamps to keep the graft in the right position. The surgeon, in fact, creates a small longitudinal incision into the vascular graft $(7-10 \mathrm{~mm})$, and inserts the graft between the two cartridge arms. The graft is attached to one small spike at the heel of the anastomosis and is temporarily secured to the cartridge with the two conduit clamps. The vascular graft must be carefully loaded onto the device, to assure a good anastomosis, and a small nick is made in the target vessel to allow insertion of the device's anvil. Once inserted, deployment is accomplished by pressing the trigger button on the handle, which first approximates the cartridge onto the vessel target and then deploys the 13 staples. At the same time, a blade located within the anvil automatically creates a vasotomy of $\sim 4.65 \mathrm{~mm}$ in length. On completion of the anastomosis, the surgeon releases the trigger, allowing the cartridge to unclamp, and then the anvil is removed from the target vessel. Hemostatic sutures are then applied as necessary to the anvil hole, toe, and heel of the anastomosis.

\section{Preparation of animals}

The healthy animals underwent ultrasound (US) scanning to evaluate the absence of anatomical variances of genitourinary apparatus and the preoperative renal resistive index (Table 1). The day before intervention, the animals fasted for $24 \mathrm{~h}$ to empty their intestine and reduce the volume of their stomach and intestinal loops. Water was forbidden $8 \mathrm{~h}$ before operation. To minimize stress during transportation from farm to the facility, animals were sedated by administration of diazepam $0.40 \mathrm{mg} / \mathrm{kg}$, xylazine $4 \mathrm{mg} / \mathrm{kg}$, and atropine $0.03 \mathrm{mg} / \mathrm{kg}$ given i.m., 
TABLE 1. Renal resistive indexes (RIs) before kidney transplant, at the end of surgery, and at 10 days after transplantation

\begin{tabular}{rccc}
\hline Pig & RI pretransplant & RI posttransplant & RI at 10 days from transplant \\
\hline 1 & 0.52 & 0.80 & (early thrombosis) \\
2 & 0.58 & 0.61 & 0.55 \\
3 & 0.61 & 0.72 & 0.54 \\
4 & 0.48 & 0.74 & 0.50 \\
5 & 0.51 & 0.50 & 0.52 \\
6 & 0.51 & 0.54 & 0.53 \\
7 & 0.56 & 0.69 & 0.55 \\
8 & 0.55 & 0.58 & 0.54 \\
9 & 0.58 & 0.75 & 0.55 \\
10 & 0.57 & 0.62 & 0.56 \\
\hline
\end{tabular}

using an $18 \mathrm{G}$ needle. Ketamine $10 \mathrm{mg} / \mathrm{kg}$ was administered during transportation to prepare animals before anesthesia.

After $10 \mathrm{~min}$, the animals were placed supine on the operating table and their legs were fastened.

Cannulation of the magna auricular vein to allow intravenous (i.v.) induction followed. The abdomen was aseptically prepared with povidone iodine. The vital functions of the animals were monitored during all phases of anesthesia.

Following premedication using ketamine (Ketavet, Farmaceutici Gellini, Peschiera Borromeo, Italy) $10 \mathrm{mg} / \mathrm{kg}$, atropine (Atropina solfato, Monico Spa, Padua, Italy) $0.03 \mathrm{mg} / \mathrm{kg}$, and diazepam (Valium, Roche, Milan, Italy) $0.4 \mathrm{mg} / \mathrm{kg}$, the animals were intubated with an orotracheal cannula by means of a dedicated laryngoscope. The anesthesia was induced with a mixture of isofluorane/oxygen. General anesthesia was maintained by isoflurane $1 \%$ to $1.7 \%$ (Rhodia Chem SpA, Ospiate di Bollate, Italy) in $50 \%$ oxygen supplemented with continuous infusion of fentanyl (Fentanest, Pfizer, Milan, Italy) $8 \mathrm{~g} / \mathrm{kg} / \mathrm{h}$ and midazolam (Ipnovel, Roche) $0.5 \mathrm{mg} / \mathrm{kg} / \mathrm{h}$.

A surgical venous access to the internal jugular vein was prepared by apposition of a tunneled double lumen catheter whose exit ports were placed posteriorly on the neck (12). From the opposite lateral side of the nec, the nervous-vascular bundle was dissected from which a piece of $7 \mathrm{~cm}$ of internal jugular vein was isolated and harvested for back table surgery, to increase the length of renal artery and vein.

\section{Preparation of kidney and organ perfusion}

Laparotomy consisted of a midline xypho-pubic incision. Intestinal loops were shifted to the left side of operative field and protected by gauze soaked in sterile warm saline.

This maneuver allowed us to expose the retroperitoneal space from the loins to the small pelvis where, in transparency, appeared, proceeding from cranial-caudal sense, the right kidney, the ureter with its gonadic satellite vessels, the aorto-iliac carrefour, and the right iliac vessels. Because of the major length of its hilum, the right kidney was preferred to the left. The external iliac artery (until the aortic bifurcation above and the internal iliac artery below) and the right iliac vein were skeletized.

The internal iliac artery and the vein were tied and cut to allow the complete elevation of iliac vessels. Once the iliac vessels were prepared and suspended with a vascular sling, a right nephrectomy by section of posterior peritoneal plane along the external side of the kidney was performed. This maneuver allowed the mobilization of the right kidney and to expose its hilum. The renal hilum was left as long as possible to make the transplantation easier. The ureter was maintained intact, being not essential to test the anastomotic device.

An $18 \mathrm{G}$ cannula was inserted into the renal artery to perform selective in situ perfusion with $300 \mathrm{~mL}$ of University of Wisconsin solution at $4^{\circ} \mathrm{C}$ by gravity, leaning

the kidney-protected by sterile cold saline soaked gauze-on a basin containing sterile granular ice positioned above the pubic symphysis (ureter was left uncut).

This amount of solution guaranteed the cooling of the kidney, as shown by color change, and the complete washing out of the residual blood from the organ.

Once the perfusion was completed, vessels were prepared separating them from the lax cellular tissue of the hilum. The graft vessels were lengthened with an uninterrupted end-to-end 7/0 Prolene anastomosis with the previously harvested $3 \mathrm{~cm}$ jugular vein graft. This was necessary to allow the utilization of the anastomotic device, as the $1 \mathrm{~cm}$ length of the vessels was less than the $3 \mathrm{~cm}$ required for handling.

\section{Transplantation}

The vessels of the graft were then disposed on the terminal part of the device by a limited spatulation in 


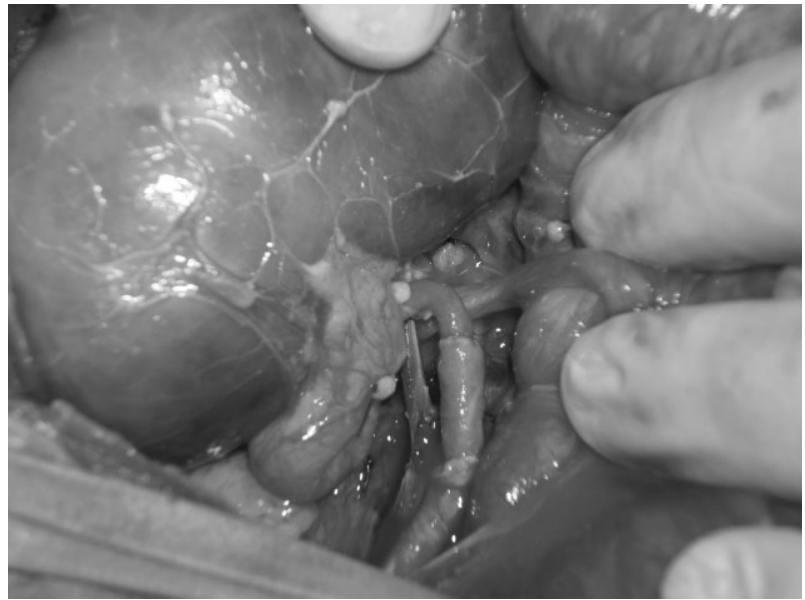

FIG. 4. Close-up showing the arterial and venous anastomoses (note the jugular vein graft).

their longitudinal axis, as described by the instructions for use provided by the manufacturer. A small incision was subsequently made on the iliac vein to allow the tangential introduction of the anvil. Once the correct positioning of the device was checked, it was armed and the end-to-side anastomosis performed. It was necessary to give a 6/0 Prolene stitch to close the vasotomy. No further stitches were needed to fix the anastomosis (Fig. 4). The same procedure was performed for the renal artery.

Abdominal wall was then closed with interrupted 2/0 Prolene stitches.

The animals were followed up with blood tests and Doppler US scanning to evaluate renal resistive index (RI), shortly after the operation and at 10 days (Table 1). US was performed by the same operator for all the animals. The US scan (MyLab 25, Esaote, Genova, Italy) was performed with a $3.5 \mathrm{MHz}$ probe. In each animal, RI at the interlobular or arcuate artery near the border of the central echo complex was measured three times in the upper, middle, and lower portions of the transplanted kidney. The mean $\mathrm{RI}$ value was used for analysis. An $\mathrm{RI}<0.6$ was considered normal. The statistical analysis was performed with Student's $t$-test comparing the mean value preoperatively and at 10 days.

\section{RESULTS}

The perfusion solution was drained by gravity and the complete washing out of clear liquid drained from the vein was completed at a mean time of $5 \mathrm{~min}$ ( $\mathrm{SD} \pm 1 \mathrm{~min}$ ).

During cold ischemia, the elongation of vessels required a mean of $8 \mathrm{~min}(\mathrm{SD} \pm 1 \mathrm{~min})$ for the renal vein and a mean of $6 \mathrm{~min}$ for the artery (SD $\pm 1 \mathrm{~min})$.
Out of the 10 pigs, we reported one case of arterial and venous thrombosis due to axial torsion of both the vessels due to a technical error, with subsequent kinking and blood stasis. In the other nine cases, the anastomoses were performed correctly.

Organ perfusion was optimally conducted as demonstrated by the homogeneous change in color of the kidneys. Once the graft vessel on the cartridge assembly was prepared carefully, the anastomoses were done quite easily and quickly. A median time of $25 \mathrm{~min} \mathrm{SD} \pm 4$ of cold ischemia and 2 min of warm ischemia (the organ removed from basin) were registered. Preparation of iliac vessel lasted a mean of $15 \mathrm{~min}(\mathrm{SD} \pm 8 \mathrm{~min})$. The organ vascularization was shown by a change in hue and diameter of the kidneys and pulsation of the renal artery.

No leakages resulted after the anvil was withdrawn along the anastomoses, except for nonmeasurable blood leaks at the insertion site of the anvil (subsequently sutured).

RI before, shortly after the operation, and at 10 days showed no significant differences $(P>0.05)$ (Table 1$)$. In particular, RIs were normal at 10 days after auto-transplantation, having slight increased values only in the immediate post-operatory period.

\section{Limitations}

The main limitation of this study is due to the differences in vascular calibers between the porcine model and the human. The device requires a learning curve before use, as the initial handling of the instrument for preparing the vessels over the cartridge assembly was difficult.

A control group was not selected because the purpose of this study was to evaluate only the feasibility of the technique.

\section{DISCUSSION}

Many devices have been developed since Carrel's first description of feasibility and significance of vascular anastomosis $(13,14)$. These devices are still burdened by several limitations that limit their routine use in clinical practice. The dream of vascular anastomosis by means of a device has been chased by different solutions, such as the employment of gastrointestinal staplers $(15,16)$.

The new application of Cardica C-Port for renal transplantation comes from the previous demonstration of its feasibility in performing arteriovenous fistula (8), given the specific properties of the device in realizing end-to-side anastomoses. The device was originally developed for coronary artery bypass surgery. The manufacturer has recently produced a 
bigger version of Cardica (Cardica vX) (17) to overcome the vascular caliber limits of Cardica C-Port Flex-A. Few data are available from the literature about the safety of Cardica, the risk of leakages, and the patency over the time, especially in the presence of vascular calcification (18). In the kidney transplantation setting, one of the problems frequently encountered is the presence of intimal calcification or arteriosclerosis of vessels and, in this regard, the safety of metallic staples should be carefully evaluated. One of the most important advantages of utilization of Cardica C-Port consists of a very short warm ischemia time of the graft if compared with an average time of 15-30 min per anastomosis in expert hands (19). Warm ischemia time is defined as the time elapsing between the removal of graft from cool storage solution and the organ reperfusion (removal of clamps from iliac vessels) or the time needed to perform anastomoses. In fact, before completing anastomoses, the graft is subject to an increase of its temperature, as it is no longer in the cold storage solution. Evidence suggests that the outcome of organ transplantation in humans is influenced by the duration of this time and not only by cold ischemia time (20-24). A prolongation of warm ischemia time is associated with delayed graft function (25) and long-term graft survival (26). A full recovery of renal function is expected for short warm ischemia time (27). Some studies suggest that warm ischemia $>30$ min results in significant immediate functional loss with either incomplete or absent late recovery $(26,28)$. The porcine model possesses a major resistance to warm ischemia (29). The warm ischemia time should be limited for humans at 20-30 $\mathrm{min}$ (30).

Furthermore, clamping iliac vessels could contribute to a further delayed function due to the release of factors responsible for ischemia-reperfusion damage, and this device limits to some extent the clamping time.

The study was conducted without a control group, with the main purpose to conduct a feasibility investigation about the potential of a device such as Cardica.

In pigs that underwent auto-transplantation, a vascular bridge of jugular vein was necessary because of the shortness of graft vessels. In fact, the device needs a comfortable operative field and a minimal length of vessel to be anastomosed, and the porcine pelvis is narrower than the human one. In this study, the mechanical end-to-side anastomosis was performed between a vein tract (jugular graft) and an artery (external iliac artery) or a vein (external iliac vein). The reason for this choice was dictated from the necessity to have an easy to obtain vascular graft, avoiding an important injury to the animal. The costs and the difficulty of such an adult model made it necessary to perform all the experimental steps in the same animal. Moreover, the conduit should have a wall thickness of $<1.4 \mathrm{~mm}$ (as in jugular vein) to allow adequate penetration of the staples and safe disengagement of the device.

Cardica C-Port permits us to obtain rapid vascular end-to-side anastomoses virtually without the need to clamp iliac vessels if the venous anastomosis is performed before the artery. The preparation of iliac vessels of the recipient needs to isolate a shorter vascular tract with a plausible reduction of incidence of postoperative lymphocele in transplanted patients (31).

The technique shown here appears easy, time saving, and could be tested for human use. Nevertheless, there is a learning curve for this device. It is a challenge, in a narrow surgical field, to be able to place the vessel correctly between the cartridge arms, and adequate experience is needed to load the device. Moreover, with Cardica C-Port Flex-A, the surgeon has a single shot per instrument.

There are financial issues regarding the cost of this device, which is around $\$ 800$ each, with a cost of $\$ 1600$ per transplant. The use of this device could be justified by the improved outcome of transplant-if confirmed from larger studies.

\section{CONCLUSION}

The purpose of this study was to demonstrate the experimental evidence of reducing drastically the warm ischemia time during organ transplant surgery by using an automatic anastomotic device.

The implementation of such a device, considering the safety regarding the absence of any bleeding and the dramatic reduction of warm ischemia time, could permit its utilization in marginal donor organs. Moreover, the charming possibility to reduce to near zero the warm ischemia time could make it attractive to use the device in living kidney donor transplantion.

Acknowledgments: The authors thank Cardica Inc. for having freely provided the staplers utilized for this study. The study was conducted in the Animal Facilities of the Laboratorio Sperimentale Animale at Istituto Zooprofilattico Sperimentale della Sicilia "A. Mirri” of Palermo, Italy. The authors thank Giovanni Cassata, responsible for the animal surgical room, for the medical assistance during the study. The authors declare they have no funding sources to disclose. 
Author contributions: A.I.L.M., G.B., and G.D. participated in research design; G.D., G.S., and A.I.L.M. participated in the writing of the paper; A.I.L.M., G.D., G.S., and V.D.P. participated in the performance of the research; V.D.P. and G.S. participated in data analysis.

\section{Conflict of Interest: None.}

\section{REFERENCES}

1. Zeebregts CJ, Kirsch WM, van den Dungen JJ, van Schilfgaarde R, Zhu YH. Evolution of staples and clips for vascular anastomoses. Int Surg 2004;89:152-60.

2. Eckstein FS, Bonilla LF, Englberger L, et al. The St Jude Medical symmetry aortic connector system for proximal vein graft anastomoses in coronary artery bypass grafting. $J$ Thorac Cardiovasc Surg 2002;123:777-82.

3. Hui KC, Zhang F, Shaw WW, et al. Learning curve of microvascular venous anastomosis: a never ending struggle? Microsurgery 2000;20:22-4.

4. Martens TP, Argenziano M, Oz MC. New technology for surgical coronary revascularization. Circulation 2006;114:60614.

5. Gambino G, Gioviale MC, Maione C, et al. Use of marginal donors in kidney transplantation: our experience. Transplant Proc 2006;38:999-1000.

6. Matschke KE, Gummert JF, Demertzis S, et al. The Cardica C-Port System: clinical and angiographic evaluation of a new device for automated, compliant distal anastomoses in coronary artery bypass grafting surgery-a multicenter prospective clinical trial. J Thorac Cardiovasc Surg 2005;130: $1645-52$.

7. Suyker W, Borst C. Coronary connector devices: analysis of 1,469 anastomoses in 1,216 patients. Ann Thorac Surg 2008; $85: 1828-36$

8. Lo Monte AI, Buscemi G. Is it possible to create a "mechanical" arteriovenous fistula in hemodialysis patients? Artif Organs 2010;34:239-41.

9. Bregy A, Alfieri A, Demertzis S, et al. Automated end-to-side anastomosis to the middle cerebral artery: a feasibility study. J Neurosurg 2008;108:567-74.

10. Hänggi D, Reinert M, Steiger HJ. C-Port Flex-A-assisted automated anastomosis for high-flow extracranial-intracranial bypass surgery in patients with symptomatic carotid artery occlusion: a feasibility study. Clinical article. J Neurosurg 2009;111:181-7.

11. Demers G, Griffin G, De Vroey G, Haywood JR, Zurlo J, Bédard M. Animal research. Harmonization of animal care and use guidance. Science 2006;312:700-1.

12. Lombardo C, Damiano G, Cassata G, et al. Surgical vascular access in the porcine model for long-term repeated blood sampling. Acta Biomed 2010;81:101-3.

13. Carrel A. La technique opératoire des anastomoses vasculaires et la transplantation des viscéres. Lyon Med 1902;98: 859-64.
14. Kovanov VV. Mechanical and hand suture of blood vessels. $\mathrm{Br}$ Med J 1956;5:1003-5.

15. Liu C, Tsai HL, Loong CC, Hsia CY, Chin T, Wei C. ENDOGIA staplers for side-to-side anastomosis of veins. Eur J Vasc Endovasc Surg 2006;32:584-8.

16. Ayad RF, Bhella PS, Dockery WD, Schussler JM. Patency of vein graft anastomoses facilitated with the hexalon device. Ann Thorac Surg 2011;91:894-8.

17. Kappert U, Ouda A, Virmani R, Mettler D, Matschke K, Demertzis $\mathrm{S}$. The $\mathrm{C}$-Port $\mathrm{xV} ®$ vascular anastomosis system: results from an animal trial. Thorac Cardiovasc Surg 2011; 59:222-8.

18. Verberkmoes NJ, Wolters SL, Post JC, Soliman-Hamad MA, ter Woorst JF, Berreklouw E. Distal anastomotic patency of the Cardica C-PORT(R) xA system versus the hand-sewn technique: a prospective randomized controlled study in patients undergoing coronary artery bypass grafting. Eur $J$ Cardiothorac Surg 2013;44:512-9.

19. Marzouk K, Lawen J, Alwayn I, Kiberd BA. The impact of vascular anastomosis time on early kidney transplant outcomes. Transplant Res 2013;2:8.

20. Peters TG, Shaver TR, Ames JE, et al. Cold ischemia and outcome in 17,937 cadaveric kidney transplants. Transplantation 1995;59:191-6.

21. Roodnat JI, Mulder PG, Van Riemsdijk IC, et al. Ischemia times and donor serum creatinine in relation to renal graft failure. Transplantation 2003;75:799-804.

22. Salahudeen AK, Haider N, May W. Cold ischemia and the reduced long-term survival of cadaveric renal allografts. Kidney Int 2004;65:713-8.

23. Van der Vliet JA, Warlé MC, Cheung CL, Teerenstra S, Hoitsma AJ. Influence of prolonged cold ischemia in renal transplantation. Clin Transpl 2011;25:E612-6.

24. Debout A, Foucher Y, Trébern-Launay K, et al. Each additional hour of cold ischemia time significantly increases the risk of graft failure and mortality following renal transplantation. Kidney Int 2015;87:343-9.

25. Halloran P, Aprile M. Factors influencing early renal function in cadaver kidney transplants. A case-control study. Transplantation 1988;45:122-7.

26. Hatsuse K, Kinukawa T, Hattori R, Fujita T, Ono Y, Ohshima $\mathrm{S}$. Cadaveric renal transplantations with prolonged warm ischemic times greater than 30 minutes. Transplant Proc 1988;30: 3787-9.

27. Novick AC. Renal hypothermia: in vivo and ex vivo. Urol Clin North Am 1983;10:637-44.

28. Hellegering J, Visser J, Kloke HJ, et al. Deleterious influence of prolonged warm ischemia in living donor kidney transplantation. Transplant Proc 2012;44:1222-6.

29. Laven BA, Orvieto MA, Chuang MS, et al. Renal tolerance to prolonged warm ischemia time in a laparoscopic versus open surgery porcine model. J Urol 2004;172:2471-4.

30. Porpiglia F, Renard J, Billia M, et al. Is renal warm ischemia over 30 minutes during laparoscopic partial nephrectomy possible? One-year results of a prospective study. Eur Urol 2007:52:1170-8.

31. Lo Monte AI, Maione C, Damiano G, et al. A case report of a difficult dissection of the iliac vessels conducted by means of the harmonic scalpel during a kidney transplantation. Clin Ter 2011;162:227-9. 